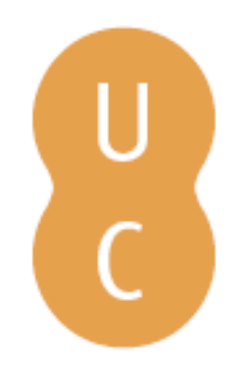

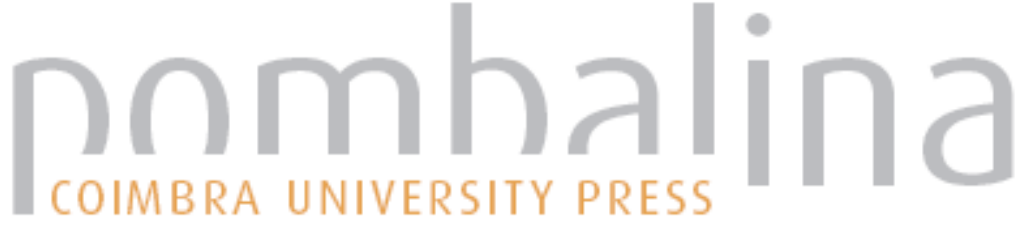

\section{As curvas do meu percurso}

Autor(es): $\quad$ Barbosa, Maria Augusta

Publicado por: Imprensa da Universidade de Coimbra

URL

persistente: URI:http://hdl.handle.net/10316.2/30032

DOI: $\quad$ DOI:http://dx.doi.org/10.14195/978-989-26-0567-8_2

Accessed : $\quad$ 26-Apr-2023 10:23:53

A navegação consulta e descarregamento dos títulos inseridos nas Bibliotecas Digitais UC Digitalis, UC Pombalina e UC Impactum, pressupõem a aceitação plena e sem reservas dos Termos e Condições de Uso destas Bibliotecas Digitais, disponíveis em https://digitalis.uc.pt/pt-pt/termos.

Conforme exposto nos referidos Termos e Condições de Uso, o descarregamento de títulos de acesso restrito requer uma licença válida de autorização devendo o utilizador aceder ao(s) documento(s) a partir de um endereço de IP da instituição detentora da supramencionada licença.

Ao utilizador é apenas permitido o descarregamento para uso pessoal, pelo que o emprego do(s) título(s) descarregado(s) para outro fim, designadamente comercial, carece de autorização do respetivo autor ou editor da obra.

Na medida em que todas as obras da UC Digitalis se encontram protegidas pelo Código do Direito de Autor e Direitos Conexos e demais legislação aplicável, toda a cópia, parcial ou total, deste documento, nos casos em que é legalmente admitida, deverá conter ou fazer-se acompanhar por este aviso.

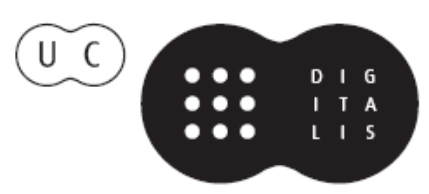




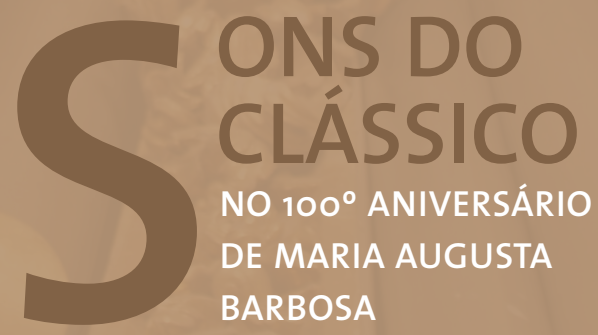

J. M. Pedrosa Cardoso

Margarida Lopes de Miranda COORDENAÇÃO 
Maria Augusta Barbosa

\section{AS CURVAS DO MEU PERCURSO ${ }^{1}$}

\section{Em jeito de introdução}

Por vários lados - e de há muito tempo já - tem-me vindo a ser pedido um relato das minhas actividades ao longo da minha vida profissional. Tenho-me sempre esquivado, na convicção de que os factos - bem ou mal - por si falam, e não vale a pena, portanto, focá-los em especial.

Mas a insistência continua e tem-me sido dito até que o meu silêncio pode dar azo a que, por desconhecimento, se venham a fazer afirmações menos certas em relação à obra realizada. E decidi-me então [...]

\section{Relato das minhas actividades}

Nasci em Lisboa, no dia 18 de Abril de 1912.

A natural inclinação que, durante a infância e a juventude, eu ia revelando para a música, levou os meus pais a orientar os meus estudos também nesse sentido. E após cuidadosos e prolongados estudos a nível particular, sempre sob a orientação de professores especializados nas áreas do ensino liceal e da música, sem esquecer a preparação visando o domínio teórico-prático das línguas francesa, inglesa e italiana, matriculei-me no Conservatório Nacional de Lisboa, único estabelecimento oficial que ao tempo, em matéria do ensino da música, existia em Portugal.

\footnotetext{
1 Título da nossa autoria.
} 
Matriculei-me nos cursos superiores de piano e de contraponto e fuga, respectivamente nas aulas dos professores José Vianna da Motta (piano) e António Eduardo da Costa Ferreira (contraponto e fuga). Terminei estes dois cursos respectivamente com 19 e 20 valores, tendo obtido classificações igualmente elevadas nos exames dos cursos de música, geral e complementar, que me haviam dado acesso aos cursos superiores acima referidos. Após a conclusão destes últimos, parti para Paris onde, durante um ano lectivo, frequentei as aulas de História da Música dirigidas pelo Prof. Louis Lalloy, no Conservatório de Música desta cidade e me aperfeiçoei em composição - prolongamento do curso de contraponto e fuga - agora sob a orientação particular da Prof ${ }^{a}$ Nadia Boulanger, ao tempo uma das mais afamadas autoridades nesta matéria, à escala internacional.

Regressei a Portugal no final desse ano lectivo, com o objectivo de me preparar, com serenidade e segurança, para um concurso a uma bolsa de estudos de longo prazo, que o Instituto de Alta Cultura anunciara ir abrir também em matéria de Ciências Musicais. Concorri e ganhei. Uma condição, porém, me era imposta: os estudos deviam ser feitos na Alemanha. À minha objecção de que eu não sabia alemão, foi respondido secamente e com determinação: se não sabe, aprenda-o.

Parti para Berlim nesse ano - Outubro de 1938 - e aí encontrei na matéria que me havia levado lá e que se não ensinava em Portugal, professores extraordinários e um nível de conhecimentos que respondia ao que eu procurava e que justificava plenamente as directivas recebidas.

Hans Mersmann, Johannes Wolf e Arnold Schering, que já faleceram, foram os professores universitários que desde logo orientaram os meus primeiros passos no sentido dos novos estudos e os guiaram até ao fim dos oito semestres requeridos pelas universidades alemãs para conclusão deste Curso de Ciências Musicais, equivalente a qualquer Curso das nossas Licenciaturas em Letras.

O meu primeiro semestre em Berlim, entre Outubro de 1938 e Fevereiro de 1939, foi consagrado intensivamente ao estudo da língua alemã, sem que eu todavia pusesse de lado os possíveis contactos com as matérias da especialidade, usando do conhecimento que tinha das línguas francesa e inglesa.

A aprovação no exame, escrito e oral, da língua alemã abriu-me o acesso à matrícula na Humboldt Universität, em Berlim. Depois, entre Fevereiro de 
1939 e Julho de 1943, levei a termo, com êxito, os oito semestres requeridos pela Universidade, apesar das dificuldades inerentes à qualidade de língua exigida numa faculdade e à vida num país em guerra, com as carências de alimentação difícil não obstante a extraordinária organização alimentar estabelecida e, por outro lado, a intensificação progressiva dos bombardeamentos.

Terminados os oito semestres requeridos pelo curso, tentei começar a recolher elementos para uma tese de doutoramento.

Ao cabo destes anos de luta, várias cidades tinham sido completamente arrasadas pelo progredir da guerra. E agora, após Hamburgo, Nurenberg e outras, era Berlim que estava em linha.

Regressei portanto a Portugal em Agosto de 1943, quando Hitler aconselhou mulheres e filhos de diplomatas a regressar aos seus países, porque não podia - disse - tomar a responsabilidade pelo que viesse a acontecer. Era de resto impossível proceder, no tempo de então, às investigações de que eu carecia. Por outro lado, fui fortemente aconselhada a regressar, pelas autoridades portuguesas diplomáticas na Alemanha. O perigo era grande, como a seguir se verificou.

Pouco depois de chegar a Portugal, fui convidada pelo Director do Conservatório Nacional - Dr. Ivo Cruz - a substituir o Prof. Eduardo Libório, recentemente falecido, na regência das disciplinas de Acústica e História da Música, de que ele fora detentor. Desempenhei este lugar de 1945 até fins de 1958, tendo conseguido tornar possível, aos meus alunos, a vivência regular dos valores musicais que eles aprendiam a conhecer histórica e analiticamente nas aulas, agora também nas próprias salas de espectáculo (óperas, bailados, concertos de orquestra, de "camera" e a solo) sempre gratuitamente, por gentileza e compreensão dos directores das respectivas organizações. Os intervalos eram sistematicamente preenchidos por trocas de impressões e de critérios analíticos entre os alunos e o professor, que sempre os acompanhava.

Sob pressão de amigos e do próprio Instituto de Alta Cultura, parti então de novo para a Alemanha, a fim de efectuar o doutoramento em Ciências Musicais (também com subsidio do Instituto de Alta Cultura), desta vez na Universidade de Colónia, já que a Humboldt Universität, em Berlim, onde eu havia feito o curso, estava agora localizada na zona Leste da Alemanha, com a qual Portugal não tinha relações diplomáticas. Em Colónia tive, por orientadores 
de tese, o meu anterior professor de Berlim, Prof. Doutor Hans Mersmann, que entretanto tinha fixado residência em Colónia, e o Prof. Doutor Karl-Gustav Fellerer, Director do Instituto de Ciências Musicais da Universidade de Colónia.

Foi-me modificado o tema de tese para outro em si mais complexo e fui obrigada a frequentar dois novos semestres nesta Universidade, por imposição de lei, que exigia esta frequência, com a apresentação dos respectivos trabalhos de seminário, a todos os alunos que transitassem de uma para outra Universidade na Alemanha, mesmo que tivessem já o curso concluído e a nova ligação à Universidade tivesse por objectivo o doutoramento.

A matéria do novo tema focava uma difícil querela renascentista sobre teoria modal, em que se tinham azedamente envolvido, por um lado, um músico português, compositor e teórico musical de valor e, por outro, um músico italiano da corte do poderoso Cardeal de Ferrara, músico igualmente teórico musical de elevado nível. Esta questão havia tomado agudas proporções e juntado, para julgamento em Roma, na Capela Papal, dois cantores / compositores desta mesma Capela e a corte cardinalícia. A temática evocava um dos problemas teórico-musicais mais escaldantes na época, porque era tempo de reforma em estrutura musical e técnica de composição.

Por outro lado ainda, eram desconhecidos dados biográficos do músico português. Apenas se supunha ser oliventino e se sabia estar ligado à casa do embaixador português em Roma, em meados do século xvi, D. Alexandre de Lencastre, e a seu filho, D. Dinis. Todos estes factos iriam mexer muito com questões de história, algumas ainda desconhecidas, obrigando a investigações de fundo, inevitavelmente demoradas. Foi necessário investigar em países diversos: Portugal (Lisboa, Coimbra, Braga, Évora, Elvas, e alguns arquivos de vilas alentejanas fronteiriças); Espanha (Madrid, Salamanca, Simancas, Escoriai, Badajoz, Olivença), Bélgica (Bruxelas), França (Strassburg, Paris); Alemanha (Munique, Ludwígsburg); Itália (cidades várias, entre as quais Roma, Pádua, Veneza, Viterbo, Bolonha).

Necessariamente demoradas, as investigações foram sempre apontadas para as Bibliotecas e Arquivos dos locais onde se admitia a hipótese de se virem a encontrar elementos de interesse para a tese em curso.

Concluída esta tese e prestadas as inerentes provas de doutoramento [no ano de 1970], de discussão oral, foi-me oferecida, por intermédio de um dos meus 
orientadores de tese - o Prof. Doutor Karl-Gustav Fellerer - uma bolsa de estudo do governo alemão - que na Alemanha apenas se concede a doutorados -, para que eu pudesse estudar e publicar um tratado manuscrito de muito valor, anónimo, que é de certeza de um músico português quinhentista que se havia fixado no estrangeiro. Apesar de recomendações e de solicitações várias de professores universitários alemães e de outras influências que se moveram, a Directora do Conservatório Nacional, ao tempo, a seguir ao Dr. Ivo Cruz que atingira a idade da reforma, em conjunto com o Director Geral do Ensino Superior, impediram que eu aceitasse a bolsa, a fim de que regressasse ao Conservatório Nacional para ensinar Acústica e História da Música - como o fizera antes do Doutoramento - agora apenas a 3 alunas com preparação cultural muito limitada. Eu tinha, nesta altura, o trabalho sobre esse manuscrito em certo andamento e até mesmo quem estivesse interessado em o publicar, trabalho que eu tinha em mente, logo que terminado - o que duraria um máximo de dois anos - apresentar como tese de agregação na Universidade de Colónia, para avançar na carreira universitária, ao mesmo tempo que fazia currículo com um estudo de muito interesse para a nossa cultura. O que então teria sido possível, não o foi depois.

Em Portugal, retomei o meu antigo lugar no Conservatório Nacional, tendo--me também então sido proibido, pela mesma Directora, que eu elaborasse os programas das minhas próprias aulas. Estes foram-me impostos. Os alunos deste ano e os do ano seguinte reagiram fortemente contra, e com razão; mas concordaram com aqueles que lhes dei logo a seguir ao 25 de Abril. Não se esqueça que eu era, nessa altura, o único cidadão português, no mundo inteiro, doutorado em Ciências Musicais, e nelas plenamente actualizado, vindo donde vinha.

Mas é evidente que eu não podia ficar aqui limitada a uma situação sem horizontes e até vexatória.

O 25 de Abril veio franquear-me uma nova pista, em parte sugerida pelo Prof. Gerhard Doderer, em vésperas de doutoramento, pista que já como que me aflorara, mas que eu, desiludida, talvez não tivesse seguido, não fora a forte pressão de G. Doderer: uma licenciatura em Ciências Musicais numa Universidade Portuguesa.

Um estudo deste problema entre mim, o Prof. Doderer e o Prof. Doutor Henrique de Oliveira Marques, Director ao tempo da Faculdade de Ciências Humanas e Sociais da Universidade Nova de Lisboa, preparou o terreno. 
Gerhard Doderer regressou à Alemanha para concluir o doutoramento; eu fiquei com o encargo de estruturar a nova licenciatura, programas inclusive, e seleccionar o núcleo docente dentro do que fosse de momento possível.

A nova licenciatura foi superiormente legalizada e ainda hoje perdura, em permanente renovação, na Faculdade de Ciências Humanas e Sociais da Universidade Nova de Lisboa.

No decurso destes primeiros tempos ia-nos caber igualmente a tarefa superior de começar a formar o futuro quadro docente deste novo ramo, o de Ciências Musicais, na Universidade Portuguesa.

De momento apenas consegui reunir, embora sem o necessário enquadramento oficial, mas com sólida preparação especializada de base, o Prof. Dr. João de Freitas Branco e a Prof ${ }^{a}$. Constança Capdeville, que haviam feito a sua elevada preparação cultural, a nível pessoal e que se revelaram neste ensino à altura das suas novas funções.

Veio juntar-se-lhes, um ano mais tarde, Gerhard Doderer, doutorado havia pouco tempo, igualmente nesta matéria, na Alemanha, na Universidade de Würzburg e, ainda algum tempo depois, Salwa Castelo Branco recentemente também doutorada, na mesma matéria, mas na Universidade de Nova York.

Ambos iriam adquirir a nacionalidade portuguesa e fixar-se em Portugal; são ambos hoje professores catedráticos da mesma faculdade.

A licenciatura em Ciências Musicais começou a funcionar em Outubro de 1980. A partir daí - e durante os dois anos seguintes - estruturei-a, orientei os programas de ensino fixados por lei, apetrechei-a com a aparelhagem que me foi dado adquirir e com a bibliografia de especialização que pude conseguir, recorrendo a centros e fundações culturais, bibliografia de que a Universidade Nova estava desprovida.

Organizei portanto a sua estrutura lectiva como a sua estrutura administrativa, no primeiro ano sem auxílio nenhum, no segundo tendo conseguido que me fosse adjudicado ao serviço um oficial de $3 a$, que ainda hoje continua ligado ao Departamento.

Na convicção de que era indispensável dar ao nosso ensino a devida projecção, dei azo, com a colaboração do Ministério da Educação e do Goethe-Institut, a realizações artístico-culturais, portanto num enquadramento internacional, neste caso sempre luso-alemão. 
Para dar aulas, lançar mãos de todos estes trabalhos, atender pessoas de fora que me procuravam para assuntos relacionados com o novo Departamento e, sobretudo, falar com os alunos, em conjunto ou em particular, e até ir ao Ministério da Educação, resolver assuntos que só pessoalmente podiam ser rapidamente tratados, passei estes dois anos inteiramente ligada, de 2.a a 6.a feira, entre as 9 horas da manhã e as 8 horas da noite, à Faculdade, hora a que esta fechava.

No final de 1982, eu tinha atingido os 70 anos de idade, limite máximo de tempo, para poder exercer as funções que estava a exercer. Tinha também 44 anos de serviço (1938-1982), porque a lei considerava então para efeitos de contagem de anos para reforma, o tempo de uma bolsa de estudos oficial, se esta tivesse revertido em benefício do país. Nunca me preocupei com o tempo que podia exceder os limites normais da minha actividade profissional, mas não estava - isso sim - interessada em ficar de braços cruzados.

Neste tempo de trabalho não me foi reconhecida, porém, a exclusividade. À minha reclamação foi respondido que a exclusividade era um simples subsídio, sem direito portanto à reforma. Cerca de um ano depois, eram diferentes os critérios; mas não fui por eles abrangida.

Terminado o meu tempo oficial de trabalho, mas sentindo eu - e os médicos consultados também - que ainda estava em condições físicas e mentais de continuar a levar por diante o projecto que tinha lançado, comecei a pensar na fundação de um mestrado em Ciências Musicais, apontando desta vez, porém, para a Universidade de Coimbra.

Conseguimos abri-lo em 1986, o Prof. Doutor G. Doderer e eu, como mestrado independente e também um pouco como pé de entrada, na esperança de poder vir um dia a criar, nesta mesma Universidade, a respectiva licenciatura.

Na programação dos seminários esteve sempre em vista a preparação do mestrando para um trabalho de investigação tendente a valorizar a cultura portuguesa, dos tempos antigos á actividade.

Daí a persistência no ensino do latim e da paleografia geral, como estavam em uso nos velhos tempos de Portugal, além das matérias da especialidade, estas variáveis de mestrado para mestrado, à luz de uma visão abrangente do conjunto Portugal/Europa. 
Este mestrado tem continuado a funcionar regularmente até ao tempo presente, tendo assim aberto o caminho, nas diversas linhas da especialidade, a um número já considerável de mestrandos, hoje mestres, todos até agora com boas colocações e com boas perspectivas de futuro. Orientados que foram no sentido de um trabalho correctamente estruturado e cientificamente elaborado, com base na análise e na investigação histórica, alguns concluíram já o doutoramento, outros estão a prepará-lo. A escolha dos temas de dissertação e de tese de doutoramento tem vindo continuamente a recair, como havia sido projectado, sobre temática de cultura musical portuguesa, nos seus diferentes quadrantes, - no sentido histórico, teórico e de música prática - trazendo á luz do dia provas da nossa cultura, que há muito viviam esquecidas no silêncio de arquivos e bibliotecas, dentro e fora do país.

Na sequência do esforço feito até hoje neste sector, verifica-se um fervilhar de interesses por este ramo de actividade e até mesmo algumas perspectivas de uma boa abertura à edição de novos estudos.

Era este também o primeiro mestrado em Ciências Musicais, em Portugal, seguindo-se-lhe, algum tempo depois, a legalização do doutoramento, evidentemente também o primeiro na especialidade.

Faltava ainda, porém, a licenciatura, mais difícil de obter em consequência dos encargos financeiros que acarretava.

Uma troca de impressões sobre este assunto com a jurista da Faculdade de Letras da Universidade de Coimbra, Dr.a Silvia Serem, abriu-me como que uma janela. E se se ligassem, numa única licenciatura em artes, as três formas de arte que naquela faculdade dessa licenciatura careciam: música, teatro, cinema? Estava aberto o caminho; só faltava trabalhar.

Começaram a dar-se, desde logo, os primeiros passos, mas só no início dos segundos Conselhos Científico e Directivo seguintes foi possível imprimir--lhes o necessário impulso.

Em reuniões consecutivas, nas quais tomaram sempre parte activa professores integrados nestes três ramos de arte, reuniões superiormente orientadas por um presidente excepcional do Conselho Científico - o Prof. Doutor Souza Ribeiro -, avançou-se ao ponto de a licenciatura em questão poder abrir em Outubro de 2002, como "Licenciatura em Estudos Artísticos". 
Dos cerca de 300 candidatos que então se inscreveram, foram seleccionados apenas 20, uma vez que, por um lado, se pretendia evitar uma proliferação de licenciados na matéria, sem colocação e, por outro lado, se entendia dever apostar na qualidade.

Simultaneamente, durante um ano lectivo, dirigi uma aula de História da Música integrada na Licenciatura em História, na Universidade Autónoma (1989-1990), Universidade da qual me transferi a seguir para a Universidade Lusíada onde, durante vários anos e até que a saúde mo permitiu (Março de 1991 a fins de 2001) tive a meu cargo a cadeira de História da Música de idêntica Licenciatura e orientei vários seminários em Cultura do Património, tendo por tema uma interligação da música com a arte plástica, no séc. 19/20, um dos quais na Universidade Lusíada, do Porto.

Razões graves de saúde, que me levaram a mais de um internamento de urgência no Hospital de Santa Maria (fins de 2001), não me permitiram colaborar, até ao fim, na composição desta licenciatura de combinação; mas eu tinha tido o cuidado de, muito tempo atrás, ter começado a preparar a futura continuação do projecto em curso, sem que se sentisse a falta da minha presença. E assim tem vindo a acontecer nos três escalões universitários das Ciências Musicais: licenciatura, mestrado e doutoramento, hoje radicados já na Universidade de Coimbra, e também na Universidade Nova de Lisboa.

Ao internamento inicial no Hospital de Santa Maria em 2001, outros de duração moderada se têm vindo a suceder, em alternância com a Casa de Saúde \& Repouso da Amoreira, na Ramada, onde acabei por ver a necessidade de definitivamente fixar residência: 2002.

Impunha-se portanto a necessidade de me desligar da minha anterior habitação, que guardava uma importante reserva de material de trabalho e cultura, recolhida no decurso de muitos anos de actividade: uma biblioteca vasta de alguns milhares de livros (c. de 8000), biblioteca bastante diversificada porque constituída ao longo de exigências pedagógicas e outras, sem contar as ofertas de centros de investigação e cultura, como Arquivo e Biblioteca Geral da Universidade de Coimbra, Academia Portuguesa de História, Fundação Calouste Gulbenkian, e outras; bem seleccionada música gravada em discos e CDs; numerosa documentação de arquivo em microfilmes e fotocópias, além de um número avultado de tratados de Teoria Musical e de 
música prática quinhentista nas respectivas edições originais, fotocópias estas, recolhidas na sua maior parte na biblioteca do Instituto de Música da Universidade de Colónia, com vista a estudos de análise de obras de música quinhentista e ao ensino da paleografia musical ocidental, vocal e instrumental, quando eu regressasse definitivamente a Portugal.

A este conjunto de materiais de trabalho, como apoio e como ponto de partida, há que acrescentar um piano de concerto Bechstein de 3/4 de cauda, em perfeito estado de conservação porque sempre muito bem cuidado.

A ideia, que eu de há muito nutria, de um dia vir a doar todo este material de trabalho a uma instituição de ensino superior que dela pudesse vir a fazer uso adequado, ideia que várias vezes, havia muitos anos também, tinha vindo a ser examinada com o actual director da Biblioteca Geral da Universidade de Coimbra, exame, mais de uma vez feito in loco, concretizou-se aquando da minha fixação na residência actual.

Saúde e idade aconselharam-me agora a pôr ponto final no exercício da minha profissão, mas não ainda na realização de trabalhos com ela relacionados.

Assim me seja facilitada a sua realização.

Nota - Este documento remonta ao ano de 2003 («Em jeito de introdução» apresenta a data de Julho de 2003) e foi escrito no Lar «Casa de Saúde e Repouso da Amoreira", a instância de pessoas amigas, tendo sido ditado à funcionária do mesmo Lar, Sónia de Carvalho, de quem nos chegou fielmente o texto. Contendo embora algumas imprecisões e omissões (como a do seu contributo na Universidade de Lisboa, de 1990 a 1995), optou-se por manter a totalidade deste original, válido como testemunho directo de uma vida. (J. M. P. C.) 